\title{
ERUPCIONES HIDROMAGMATICAS EN EL VOLCANISMO CUATERNARIO DE OLOT (GIRONA) ${ }^{(1)}$
}

\author{
J. Martí(*) y J. M. ${ }^{a}$ Mallarach (**)
}

\begin{abstract}
RESUMEN
En el presente trabajo se pone de manifiestso la importancia del volcanismo explosivo en el marco del volcanismo cuaternario de Girona, especialmente en la zona de Olot donde se concentran los episodios más recientes. Se han reconocido catorce edificios volcánicos que presentan alguna fase explosiva freatomagmática o freática durante su evolución. La actividad hidromagmática da lugar a una amplia diversidad de depósitos piroclásticos, cuyo estudio ha permitido distinguir varias secuencias eruptivas entre estos volcanes. Las diferencias en el comportamiento explosivo de unos volcanes a otros son debidas fundamentalmente a las distintas formas de interacción agua/magma en cada volcán, las cuales están determinadas por la estructura geológica de los últimos centenares de metros de la corteza y, especialmente, por las características hidrogeológicos del terreno.
\end{abstract}

Palabras clave: Volcanismo cuaternario, hidromagmatismo, secuencias eruptivas, depósitos piroclásticos.

\begin{abstract}
This paper makes clear the importance of the explosive volcanism in the field of the quaternary volcanism of Girona, especially in Olot area where the most recent episodes are concentrated.

Fourteen volcanic cones undergoing some phreatomagmatic or phreatic explosive phases during their evolution have been identified. The hydromagmatic activity gives rise to a wide variety of pyroclastic deposits, whose study has enable to distinguish several eruptive sequences in these volcanoes. The differences of explosive behaviour among the different kinds of volcanoes are due, basically, to the different ways of water/magma interaction in each volcano, which are determined by the geological structure of the last hundreds of metres of the crust and, especially, by the hydrogeological features of the ground.
\end{abstract}

Key words: Quaternary volcanism, hydromagmatism, eruptive sequences, pyroclastic deposits.

\section{Introducción}

El volcanismo del NE de Cataluña es de naturaleza alcalina y de tipo intraplaca (Araña et al., 1983; López Ruiz y Rodríguez Badiola, 1985; Guérin et al., 1986) y está representado casi exclusivamente por basaltos olivínicos y basanitas. Tanto los datos estructurales como los petrológicos y los geoquímicos apoyan el origen mantélico de los magnas. Dicho volcanismo correspondería a un modelo de rift embrionario sin antenuación litosférica y con escasas manifestaciones eruptivas (Araña et al., 1983; Guérin et al., 1986), que estaría relacionado con la última etapa distensiva del sistema de rifts europeo (Araña et al., 1983; López Ruiz y Rodríguez Badiola, 1985). La escasa variación geoquímica que presentan las lavas demuestra que los magmas alcanzaron rápidamente la superficie sin detenerse en cámaras magmáticas superficiales (Araña et al., 1983; López Ruiz y Rodríguez Badiola, 1985), representando cada volcán el testigo en superficie de zo-

(1) La realización de este estudio ha sido subvencionada por el Servei Geològic de la Generalitat de Catalunya.

$\left(^{*}\right)$ Instituto Jaime Almera, CSIC, c/ Martí i Franqués, s/n. 08028 Barcelona.

$\left(^{* *}\right)$ Parque Natural de la Zona Volcánica de la Garrotxa. Ctra. Santa Coloma, s/n. Olot (Girona). 
nas subcrustales independientes afectadas por fusión parcial (López Ruiz y Rodríguez Badiola, 1985; Guérin et al., 1986).

La localización de los centros eruptivos está relacionada con el sistema de fracturas distensivas postalpinas, con un movimiento vertical importante, que configuran una distribución en bloques de esta zona (Solé Sabarís, 1962; Riba, 1975; Donville, 1976; Solé Sugrañes, 1978; Araña et al., 1983). De esta forma, el volcanismo reciente del NE de Cataluña puede agruparse en tres unidades: Empordà, La Selva y La Garrotxa, correspondiendo cada una de ellas a distintas depresiones tectónicas.

La edad del volcanismo gerundense abarca desde unos 10 m.a. para la comarca del Alt Empordà, hasta 11.500 años en La Garotxa (Donville, 1975; Guérin et al., 1986). Así pues, la actividad volcánica evolucionó temporalmente y de forma paralela a la tectónica desde la zona más externa (Empordà) a la zona más interna (La Garrotxa) (Donville, 1976; Araña et al., 1983), observándose un ligero incremento de la alcalinidad en este mismo sentido (Araña et al., 1983).

En general se ha considerado como estromboliana la actividad característica de este volcanismo, reconociéndose únicamente al volcán Closa de Sant Salmai y Puig de Banya de Bóc como únicos representantes claros de una actividad explosiva (Tournon, 1968). Sin embargo, la cartografía y estudio detallado de estos edificios volcánicos ha permitido reconocer la importancia de las erupciones hidromagmáticas en este volcanismo (Mallarach, 1982; Mallarach et al., 1987; Martí et al., 1986).

\section{El volcanismo de Olot: características generales}

En esta zona se reconocen un total de 40 edificios volcánicos más o menos bien conservados, los cuales pueden agruparse en dos conjuntos, uno en el sector $\mathrm{N}$, que correspondería a la cuenca alta del río Fluviá y otro en el sector $\mathrm{S}$, que coincide con la cuenca media del río Ter. El principal núcleo volcánico se encuentra en el sector $\mathrm{N}$, donde existen unos 28 edificios, mientras que el sector $\mathrm{S}$ únicamente contiene una decena de ellos, aunque son los de mayores dimensiones.

En el sector $\mathrm{N}$ el volcanismo aflora sobre la serie sedimentaria eocéncia, mientras que en el sector $\mathrm{S}$ lo hace sobre los granitoides y rocas metamórficas del zócalo. La estructura de esta zona está configurada por un conjunto de bloques que se van hundiendo progresivamente de $W$ a $E$. Esta red de fracturación condiciona tanto la loca- lización de los centros eruptivos como el modelado del relieve y la disposición de la red fluvial.

La actividad volcánica en esta zona durante el Cuaternario tiene lugar de forma esporádica desde hace 350.000 años hasta unos 11.000 años, produciéndose un episodio eruptivo cada 15.000 a 20.000 años (Guérin et al., 1986).

De los volcanes reconocidos al menos catorce presentan evidencias claras de la existencia de fases hidromagmáticas durante su evolución, siendo posible distinguir diversos mecanismos eruptivos (erupciones estrombolianas, freáticas o freatomagmáticas), así como diferentes secuencias eruptivas de unos volcanes a otros.

\section{Tipos de edificios volcánicos y actividad hidromagmática}

La mayoría de los edificios volcánicos son de carácter monogénico, ya que se construyen durante una única etapa eruptiva, aunque dentro de ella sea posible distinguir varias fases que, eventualmente, puedan mostrar cierta separación temporal entre sí.

Se pueden considerar dos grupos de edificios volcánicos: los que presentan una actividad típicamente estromboliana y los que han experimentado alguna fase explosiva hidromagmática. En el primer caso, los edificos están representados por conos de cinder, simétricos o, más frecuentemente, en herradura, construidos por la acumulación de lapilli y escorias, con emisiones ocasionales de coladas de lava. Ejemplos de este tipo de actividad los encontramos en los volcanes Croscat, Montsacopa, Puig Alós, Puig de Martinyà, Artigues Roges, etc.

Los edificios con actividad hidromagmática (fig. 1) son mucho más complejos, aunque morfológicamente puedan confundirse con los anteriores. En ellos pueden alternar fases freáticas, producidas por explosiones de vapor que arrastran únicamente material del substrato, con fases freatomagmáticas que presentan distintos valores en la relación de interacción agua/magma, con fases típicamente estrombolianas. Las secuencias eruptivas resultantes, deducidas mediante el estudio de los depósitos piroclásticos, muestran variaciones importantes de unos edificios a otros, lo que indica el distinto comportamiento eruptivo de los mismos, seguramente debido a diferencias locales del substrato, en especial en lo que a sus características hidrogeológicas se refiere. En la tabla 1 se indican los edificios volcánicos con actividad hidromagmática, su secuencia eruptiva y los depósitos piroclásticos que la configuran (expresados de base a techo), así como un orden de 
Tabla 1.-Principales características de los edificios hidromagmáticos del volcanismo cuaternario de Girona.

\begin{tabular}{|c|c|c|c|c|c|}
\hline Volcán & $\begin{array}{l}\text { Secuencia eruptiva } \\
\text { (fases) }\end{array}$ & $\begin{array}{l}\text { Depósitos } \\
\text { piroclásticos }\end{array}$ & $\begin{array}{c}\text { Volumen total } \\
\text { aproximado de } \\
\text { material emitido }\end{array}$ & $\begin{array}{l}\text { Altura } \\
\text { del cono }\end{array}$ & $\begin{array}{l}\text { Dimensiones } \\
\text { del cráter }\end{array}$ \\
\hline Closa de Sant Dalmai. & $\begin{array}{l}\text { (Edificio de tipo maar) } \\
\text { freática-freatomag- } \\
\text { mática-estromboliana- } \\
\text { freática (freatomag- } \\
\text { mática)-freatomag- } \\
\text { mática-estromboliana. }\end{array}$ & $\begin{array}{l}\text { Brecha de explosión- } \\
\text { alternancias de nive- } \\
\text { les de caída y de } \\
\text { oleadas piroclásticas } \\
\text { piroclásticas secas- } \\
\text { lapillis y escorias-alter- } \\
\text { nancias de niveles de } \\
\text { caída y de oleadas pi- } \\
\text { roclásticas secas-oleada } \\
\text { piroclástica húmeda- } \\
\text { cono de cinder. }\end{array}$ & 120 a $140 \mathrm{Hm}^{3}$ & $\begin{array}{l}\text { Cono principal } \\
70 \mathrm{~m} \text {. } \\
\text { Cono secundario } \\
30 \mathrm{~m} \text {. }\end{array}$ & $\begin{array}{l}\text { Cráter de explosión } \\
1.200 \mathrm{~m} . \emptyset \\
\text { Cono estromboliano } \\
\text { desbrechado de unos } \\
300 \mathrm{~m} . \emptyset\end{array}$ \\
\hline Puig D'Adri . . . . . & $\begin{array}{l}\text { Estromboliana-freato- } \\
\text { magmática-estrombo- } \\
\text { liana-freatomagmática- } \\
\text { estromboliana. }\end{array}$ & $\begin{array}{l}\text { Oleada piroclástica } \\
\text { seca-alternancia de- } \\
\text { oleadas piroclásticas } \\
\text { húmedas y secas, inter- } \\
\text { caladas con niveles de } \\
\text { caída-lapillis y esco- } \\
\text { rias. }\end{array}$ & 100 a $120 \mathrm{Hm}^{3}$ & $160 \mathrm{~m}$. & $\begin{array}{l}\text { Desbrechado, } 500 \text { por } \\
750 \mathrm{~m} \text {. }\end{array}$ \\
\hline Clot de L'Omera .. & Freática. & $\begin{array}{l}\text { Brechas de explosión y } \\
\text { niveles de caída. }\end{array}$ & 7 a $8 \mathrm{Hm}^{3}$ & - & $\begin{array}{l}\text { Elíptico, de } 380 \text { por } \\
240 \mathrm{~m} .\end{array}$ \\
\hline Puig de Banya de Bóc. & $\begin{array}{l}\text { Freatomagmática-es- } \\
\text { tromboliana-freato- } \\
\text { magmática-estrombo- } \\
\text { liana. }\end{array}$ & $\begin{array}{l}\text { Oleadas piroclásticas } \\
\text { secas-escorias solda- } \\
\text { das y lapilli-oleadas } \\
\text { piroclásticas húmedas- } \\
\text { lavas basálticas. }\end{array}$ & 45 a $50 \mathrm{Hm}^{3}$ & $\begin{array}{l}180 \mathrm{~m} \text {. adosado a } \\
\text { un paleorelieve. }\end{array}$ & $\begin{array}{l}\text { Cráter desbrechado de } \\
1.300 \text { por } 860 \mathrm{~m} \text {. y } \\
100 \mathrm{~m} \text {. de profundi- } \\
\text { dad. }\end{array}$ \\
\hline Puig de Granollers . & $\begin{array}{l}\text { Freatomagmática-es- } \\
\text { tromboliana-freato- } \\
\text { magmática-estrombo- } \\
\text { bliana. }\end{array}$ & $\begin{array}{l}\text { Brecha de explosión- } \\
\text { escoria soldada-lavas } \\
\text { basaniticas-oleadas } \\
\text { piroclásticas secas y } \\
\text { húmedas-lavas basa- } \\
\text { níticas y escorias. }\end{array}$ & 7 a $8 \mathrm{Hm}^{3}$ & $\begin{array}{l}200 \mathrm{~m} \text {. adosado a } \\
\text { un paleorelieve. }\end{array}$ & $\begin{array}{l}\text { Cráter desbrechado } \\
500 \times 360 \text {. }\end{array}$ \\
\hline $\begin{array}{l}\text { Puig de les Medes, Lla- } \\
\text { cunagra, Puig Rodó. }\end{array}$ & $\begin{array}{l}\text { Estromboliana-freática- } \\
\text { estromboliana. }\end{array}$ & $\begin{array}{l}\text { Lapillis y lavas basál- } \\
\text { ticas. } \\
\text { Brecha de explosión. } \\
\text { Escorias y lavas. }\end{array}$ & Indet. & $\begin{array}{l}\text { Puig Medes, } 65 \mathrm{~m} . \\
\text { Puig Rodó, } 65 \mathrm{~m} .\end{array}$ & $\begin{array}{l}\text { Cráter desbrechado de } \\
230 \times 350 \mathrm{~m} \text {. } \\
\text { Llacunagra: cráter de } \\
\text { explosión } 220 \mathrm{~m} . \emptyset\end{array}$ \\
\hline $\begin{array}{c}\text { Puig de la Codina, } \\
\text { Traiter } \ldots \ldots \ldots\end{array}$ & $\begin{array}{l}\text { Estromboliana-freática- } \\
\text { freática. }\end{array}$ & $\begin{array}{l}\text { Lavas, lapillis y esco- } \\
\text { rias. } \\
\text { Brecha de explosión. } \\
\text { Brecha de explosión. }\end{array}$ & Indet. & $\begin{array}{l}\text { Puig de la Codina } \\
\qquad 120 \mathrm{~m} .\end{array}$ & $\begin{array}{l}\text { Cráter desbrechado de } \\
200 \times 280 \mathrm{~m} . \\
\text { Traiter inf. } 300 \mathrm{~m} . \emptyset \\
\text { Traiter sup. } 220 \mathrm{~m} . \emptyset\end{array}$ \\
\hline Can Tià $\ldots . . .$. & $\begin{array}{l}\text { Estromboliana-freato- } \\
\text { magmática. }\end{array}$ & $\begin{array}{l}\text { Lapillis y escorias solda- } \\
\text { das-oleadas piroclás- } \\
\text { ticas húmedas. }\end{array}$ & 0,15 a $0,20 \mathrm{H}^{3}$ & - & $270 \mathrm{~m} . \emptyset$ \\
\hline Santa Margarida ... & $\begin{array}{l}\text { Estromboliana-freato- } \\
\text { magmática. }\end{array}$ & $\begin{array}{l}\text { Lapillis y escorias-olea- } \\
\text { das piroclásticas secas. }\end{array}$ & 0,1 a $0,30 \mathrm{H}^{3}$ & $85 \mathrm{~m}$. & $450 \mathrm{~m} . \emptyset$ \\
\hline
\end{tabular}


Tabla 1.-Continuación

\begin{tabular}{|c|c|c|c|c|c|}
\hline Racó . . . . . . . . & $\begin{array}{l}\text { Estromboliana-freática- } \\
\text { estromboliana. }\end{array}$ & $\begin{array}{l}\text { Lapillis-brecha de ex- } \\
\text { plosión-lapillis. }\end{array}$ & Indet. & Superior a $150 \mathrm{~m}$. & $150 \mathrm{~m} . \emptyset$ \\
\hline Can Simó $\ldots \ldots$ & $\begin{array}{l}\text { Freatomagmática-estrom- } \\
\text { boliana-freatomag- } \\
\text { mática-estromboliana. }\end{array}$ & $\begin{array}{l}\text { Oleadas piroclásticas hú- } \\
\text { medas-escorias-olea- } \\
\text { das piroclásticas hú- } \\
\text { medas-escorias solda- } \\
\text { das y colada basáltica. }\end{array}$ & Indet. & $60 \mathrm{~m}$. & $\begin{array}{l}\text { Cráter desbrechado de } \\
300 \times 360 \mathrm{~m} \text {. }\end{array}$ \\
\hline Garrinada ..... & $\begin{array}{l}\text { Estromboliana-freto- } \\
\text { magmática. }\end{array}$ & $\begin{array}{l}\text { Colada basanítica, } \\
\text { lapillis y escorias, } \\
\text { oleadas piroclásti- } \\
\text { cas húmedas y ni- } \\
\text { veles de caída. }\end{array}$ & $0,5 \mathrm{Hm}^{3}$ & Superior a $120 \mathrm{~m}$. & $\begin{array}{l}\text { Infreior }-275 \mathrm{~m} . \varnothing \\
\text { Medio }-300 \mathrm{~m} . \varnothing\end{array}$ \\
\hline
\end{tabular}

Plaça Ribera ... $\quad \begin{gathered}\text { Freatomagmática-es- } \\ \text { tromboliana. }\end{gathered} \begin{gathered}\text { Oleada piroclástica } \\ \text { húmeda-colada } \\ \text { basanítica y lapilli. }\end{gathered}$

\begin{tabular}{|c|c|c|c|c|c|}
\hline Cairat $\ldots \ldots \ldots$ & $\begin{array}{l}\text { Freática-freatomag- } \\
\text { mática (varias } \\
\text { fases). }\end{array}$ & $\begin{array}{l}\text { Brecha de explosión- } \\
\text { lapillis (con abun- } \\
\text { dancia de líticos)- } \\
\text { oleadas piroclás- } \\
\text { ticas secas y hú- } \\
\text { medas. }\end{array}$ & 8 a $10 \mathrm{Hm}^{3}$ & - & $110 \mathrm{~m} . \varnothing$ \\
\hline
\end{tabular}

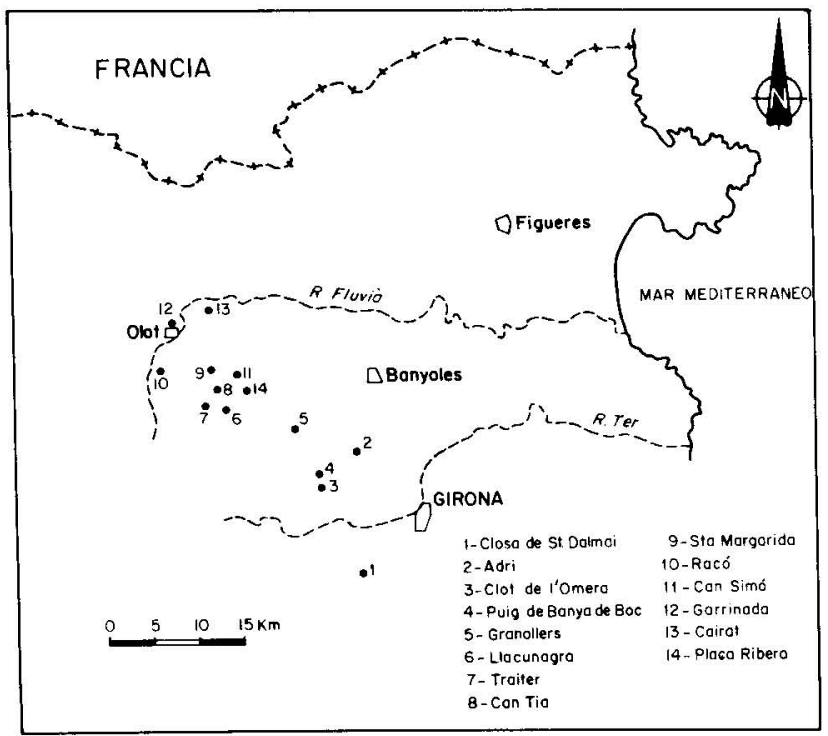

Fig. 1.-Localización de los edificios volcánicos hidromagmáticos cuaternarios.

magnitud para cada uno de ellos representado por el volumen de material emitido en los episodios hidromagmáticos y por las dimensiones del cono resultante.
Los depósitos piroclásticos producidos durante las fases explosivas hidromagmáticas son muy diversos y pueden variar notablemente de unos volcanes a otros. Se han reconocido brechas de explosión constituidas únicamente por fragmentos líticos del substrato, depósitos de oleadas piroclásticas secas y húmedas y una amplia variedad de depósitos piroclásticos de caída. Esta diversidad de depósitos depende de los distintos mecanismos eruptivos que intervienen en cada volcán, los cuales están condicionados principalmente por el valor de la relación agua/magma y por la geometría de la zona de contacto entre ambos.

A continucación se describen las secuencias eruptivas de los volcanes que presentan una más o menos intensa actividad hidromagmática.

\section{Volcanes Puig de les Medes y Racó}

Los volcanes Puig de les Medes y Racó presentan entre una fase inicial estromboliana y otra terminal del mismo tipo, una fase explosiva freática intercalada, la cual está producida por explosiones de vapor sin que exista mezcla con el magma juvenil. En el caso del volcán Puig de les Me- 
des la explosión freática afecta a una parte periférica del cono estromboliano, originándose un cráter de explosión denominado Llacunagra, topónimo evocador de un «maar» colmatado. Este hecho podría explicarse por el calentamiento y posterior explosión de un aquífero confinado que no estaría situado directamente sobre el eje magmático principal, sino sobre alguna de sus ramificaciones.

El volcán Racó constituye uno de los ejemplos más singulares del volcanismo explosivo de Olot. Se trata de un cono simétrico construido por acumulación de lapillis y escorias, en cuya zona intermedia se sitúa un nivel que contiene grandes bloques de areniscas de la Formación Bellmunt (Eoceno). Dicho nivel, de unos $10 \mathrm{~m}$ de potencia, representa una fase freática producida por la vaporización de un acuífero de pequeñas dimensiones que estaría situado en estos materiales sedimentarios, sin que se llegue a producir la interacción directa entre el magma y el agua de dicho acuífero.

\section{Volcán Traiter}

El volcán Traiter presenta una primera fase de actividad estromboliana con emisión de una extensa colada de lava basáltica y construcción de un cono de cinder desbrechado, el Puig de la Codina.

Las dos fases siguientes son de origen freático y periféricas respecto al centro emisor principal, como sucedía con la del volcán Puig de les Medes. Ambas generan cráteres de explosión causantes de la destrucción de parte del cono de cinder.

\section{Volcanes Can Tià, Garrinada y Santa Margarida}

Estos volcanes constituyen un ejemplo de interacción agua/magma en un estadio avanzado del proceso eruptivo. El volcán Can Tià inicia su actividad con un dinamismo estromboliano que genera depósitos de escorias y lapillis, con algunas bombas. Seguidamente, y de manera gradual al principio, van apareciendo fragmentos de materiales sedimentarios eocénicos, lo que indica el inicio de la interacción con un acuífero profundo, dando lugar finalmente a la deposición de una oleada piroclástica húmeda de $3 \mathrm{~m}$ de potencia (fig. 2). El estudio de los fragmentos líticos encontrados en este depósito, así como de los que aparecen a techo de los niveles de escorias, indica que el proceso de interacción agua/magma tuvo lugar en un acuífero confinado que se situaría a unos $400 \mathrm{~m}$ por debajo de la boca eruptiva.

El volcán La Garrinada también inicia su actividad con un dinamismo estromboliano que edifica un cono de escorias y emite extensas coladas basaníticas en dos episodios consecutivos. Seguidamente, y de forma gradual, van apareciendo materiales arrancados del zócalo sedimentario que se depositan en niveles de oleadas piroclásticas y de caída en los bordes del segundo y tercer cuadrante del cráter inferior, siendo la profundidad de interacción del magma con el agua meteórica menor que en el caso del volcán Can Tià. Asimismo, es probable que el depósito de oleada piroclástcia húmeda, de unos $3 \mathrm{~m}$ de potencia y que aflora $1 \mathrm{~km}$ al $\mathrm{SE}$ del volcán adosado a un relieve prevolcánico, esté relacionada con el último episodio hidromagmático.

El volcán Santa Margarida presenta la misma secuencia eruptiva que el Can Tià. El episodio estromboliano, sin embargo, edifica un cono de cinder de dimensiones considerables, mientras que los depósitos producidos durante la fase freatomagmática corresponden a oleadas piroclásticas secas, con proyección de bloques de lava que superan $1 \mathrm{~m}$ de diámetro, lo que demuestra una relación agua/magma inferior y con una energía mucho más elevada que en el caso de los volcanes Can Tià y Garrinada. El abrupto cráter circular, con una profundidad inicial superior a $85 \mathrm{~m}$ y que destruye parte del zócalo eocénico, es otra evidencia de la intensidad de la fase explosiva.

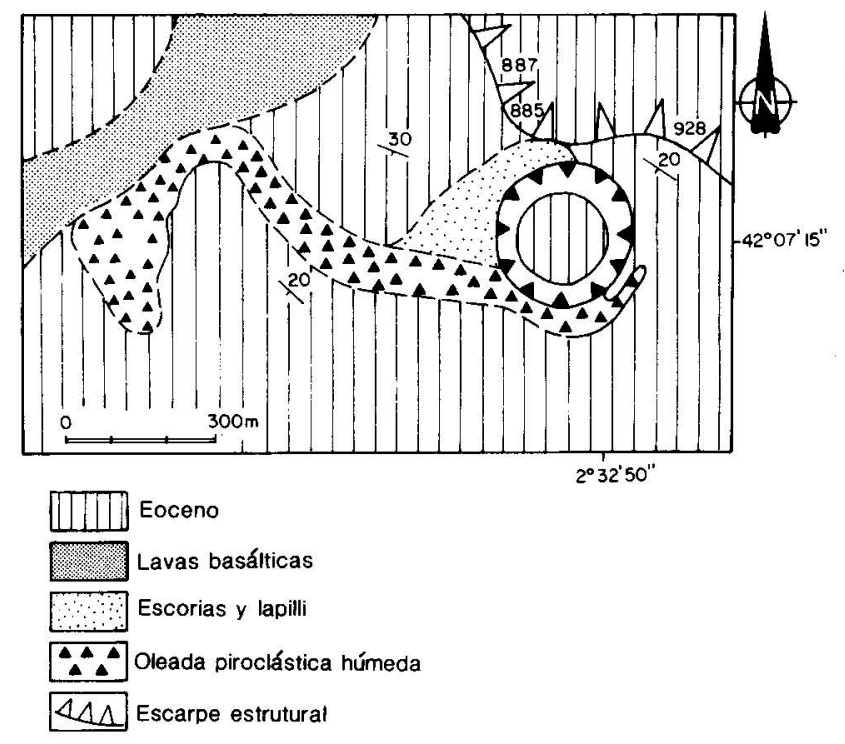

Fig. 2.-Esquema geológico del volcán Can Tià. 


\section{Volcán Plaça Ribera}

El volcán Plaça Ribera presenta una secuencia eruptiva inversa a la descrita anteriormente, puesto que inicia la actividad con una erupción freatomagmática que proyecta una oleada piroclástica húmeda de $1 \mathrm{~m}$ de potencia y unos $2 \mathrm{~km}$ de longitud. Sigue un episodio estromboliano que emite una extensa colada basanítica y edifica un cono de cinder.

\section{Volcanes Puig de Banya de Bóc, Can Simó y Puig de Granollers}

El volcán Puig de Banya de Bóc (fig. 3) es el más complejo de la región. Presenta varias alternancias de fases freatomagmáticas y estrombolianas, hecho que demuestra una interacción agua/ magma intermitente.

La erupción comienza con unas fuertes explosiones freatomagmáticas que generan varios depósitos de oleadas piroclásticas secas (fig. 4). Estos depósitos, finamente estratificados, tienen unos $3 \mathrm{~m}$ de potencia y presentan gradaciones inversas y estructuras sedimentarias unidireccionales. La relación agua/magma, durante esta fase debe considerarse óptima (entre 0,1 y 0,3 , según los modelos de Sheridan y Wohletz, 1981 y 1983 ; Wohletz y McQueen, 1984) para la conversión de la energía térmica en mecánica, tal como lo indica la granulometría cinerítica que presentan estos depósitos. Seguidamente tiene lugar una fase estromboliana, con deposición de lapillis y escorias junto a coladas de lava poco extensas, de $2-3 \mathrm{~m}$ de potencia, lo que marca una interrupción del proceso hidromagmático.

A continuación tiene lugar una nueva fase freatomagmática con formación de un depósito masivo de oleada piroclástica húmeda, de unos $20 \mathrm{~m}$ de potencia, que incluye grandes bombas del tipo coliflor. Este depósito demuestra que la relación agua/magma durante esta fase explosiva es superior a la primera, existiendo un exceso de agua que se traduce en la deposición de esta oleada de características húmedas. Nuevamente se interrumpe el proceso hidromagmático, dando lugar a otra fase estromboliana con deposición de lapillis, escorias y emisión de diversas coladas de lava basanítica, con las que se cierra el ciclo eruptivo de este volcán.

El volcán Can Simó presenta la misma secuencia eruptiva que el anterior aunque los depósitos freatomagmáticos son siempre de tipo húmedo y de muy poca potencia - de algunos decímetros hasta $1 \mathrm{~m}$ - La última fase edifica un cono de escorias soldadas con grandes bombas aplastadas y emite una colada basáltica.

El volcán Puig de Granollers empieza con una actividad freatomagmática que genera una brecha de explosión de unos $4 \mathrm{~m}$ de potencia. Siguie la emisión de pequeñas coladas basaníticas fluidas y escoriáceas acompañadas de proyección de lapilli. Un nuevo episodio freatomagmático genera oleadas piroclásticas húmedas y secas de unos $5 \mathrm{~m}$ de potencia y $3,5 \mathrm{~km}$ de longitud. La actividad eruptiva termina con la emisión de una gran colada basanítica y construcción simultánea de un cono de escorias soldadas.

\section{Volcán Clot de l'Omera}

El Clot de l'Omera es un volcán que está asociado al Puig de Banya de Bóc (fig. 3) y que, con toda seguridad, se generó durante el mismo período eruptivo. Este volcán muestra únicamente actividad freática. Está constituido por niveles masivos de brechas de explosión, compuestas por fragmentos heterométricos del substrato, que alternan con niveles más finos y mejor clasificados

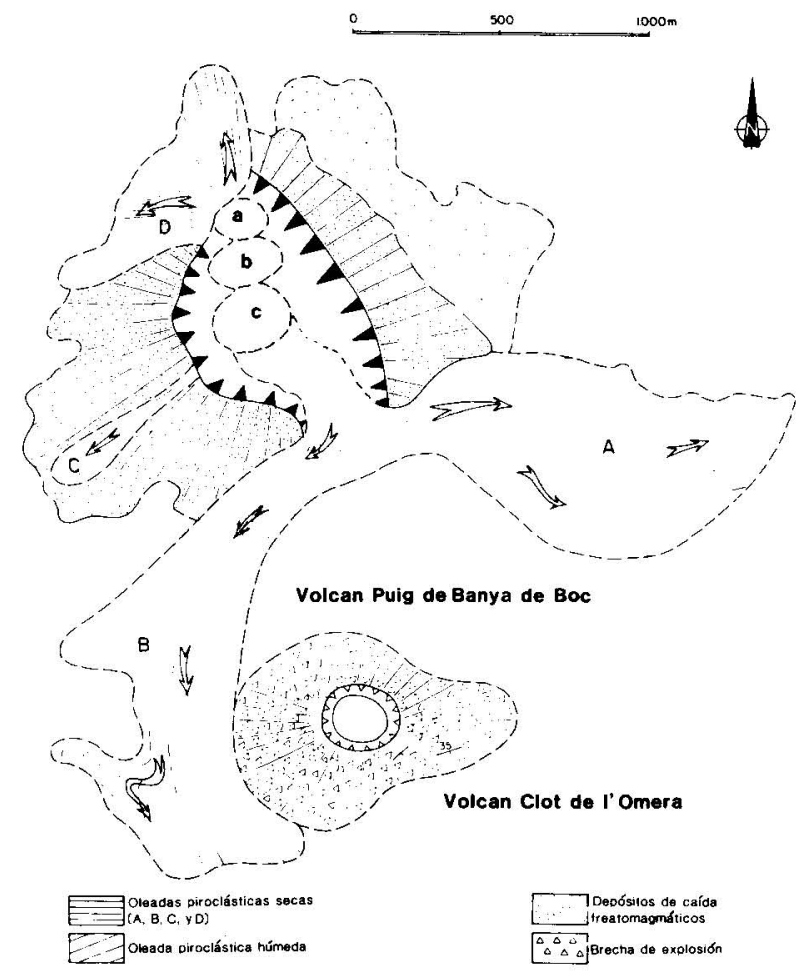

Fig. 3.-Esquema geológico de los volcanes Puig de Banya de Bóc y Clot de L'Omera. Las letras A, B y C en el interior del cráter indican la evolución de la boca de emisión durante los episodios explosivos. 
de piroclastos de caída que presentan la misma composición.

La génesis de esta volcán puede explicarse mediante una sucesión de explosiones producidas en una parte distal del acuífero que intervenía en la formación del volcán Banya de Bóc, debido al calentamiento que provocaría una lámina de magma basáltico situada debajo de él, sin que se produjera ningún tipo de interacción directa de ésta con el agua del acuífero.

\section{Volcán Puig d'Adri}

Se trata de otro gran edificio complejo similar al Puig de Banya de Bóc. Inicia su actividad con proyección de escorias y lapillis simultáneamente a la emisión de una gran colada de lava. Después de una pausa registrada por el depósito de una terraza aluvial del río Llemena, proyecta una potente oleada piroclástica húmeda que supera los

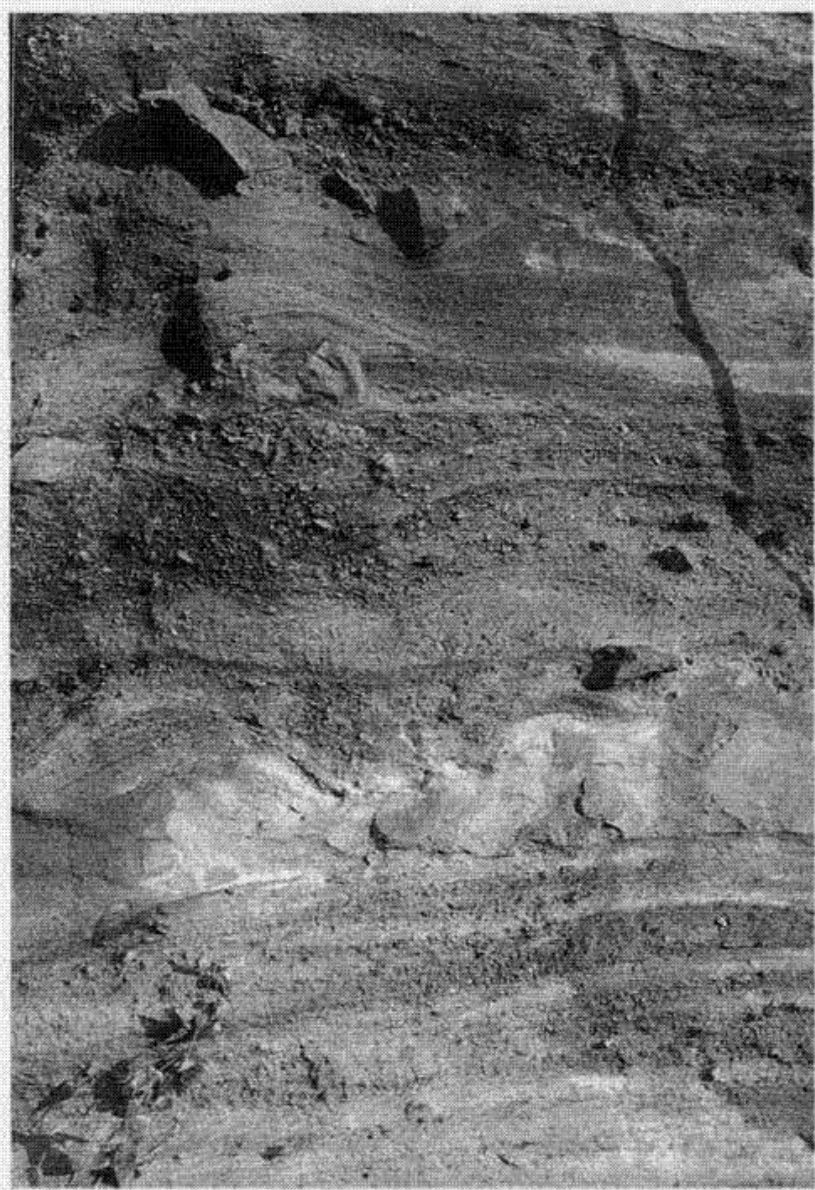

Fig. 4. - Secuencias de olcadas piroclasticas secas originadas por el volcán Puig de Banya de Bóc.
$20 \mathrm{~m}$ de potencia y $\operatorname{los} 3 \mathrm{~km}$ de longitud. Seguidamente se intercalan episodios freatomagmáti$\cos$, con alternancias de oleadas piroclásticas húmedas y secas y lapillis. Termina con la emisión de otra extensa colada basáltica y proyección de cinder (fig. 5).

\section{Volcain Cairat}

Este edificio volcánico (fig. 6) se ha construido únicamente a partir de erupciones freatomagmáticas. El estudio de sus depósitos piroclásticos permite diferenciar tres fases eruptivas, observándose un incremento progresivo de la relación agua/magma de la primera a la última.

La primera fase eruptiva da lugar a una potente brecha de explosión formada por grandes bloques (hasta de $2 \mathrm{~m}$ de diámetro) de rocas del substrato eocénico, junto con algunas bombas armadas y una cantidad apreciable de lapilli. En la

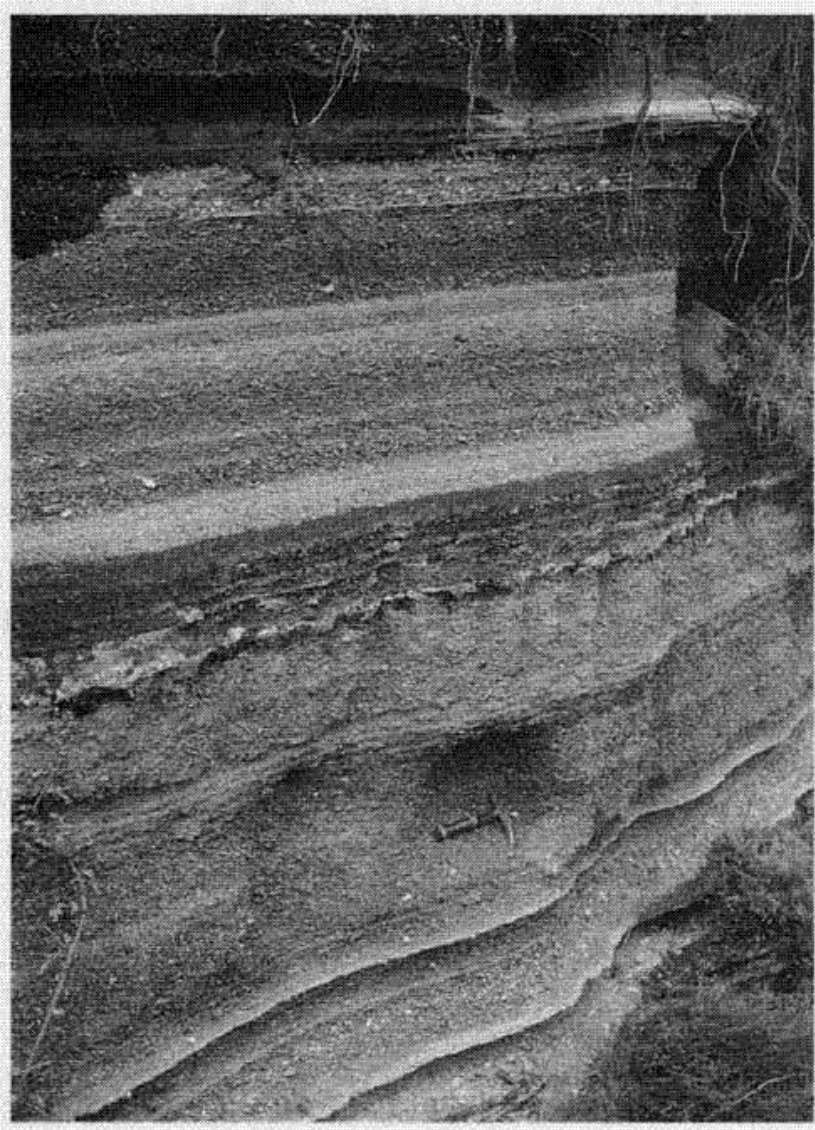

Fig. 5.-Aternancia de depósitos de proyección aérea freatomagmáticos y de oleadas piroclásticas secas en el volcán Puig d'Adri. 


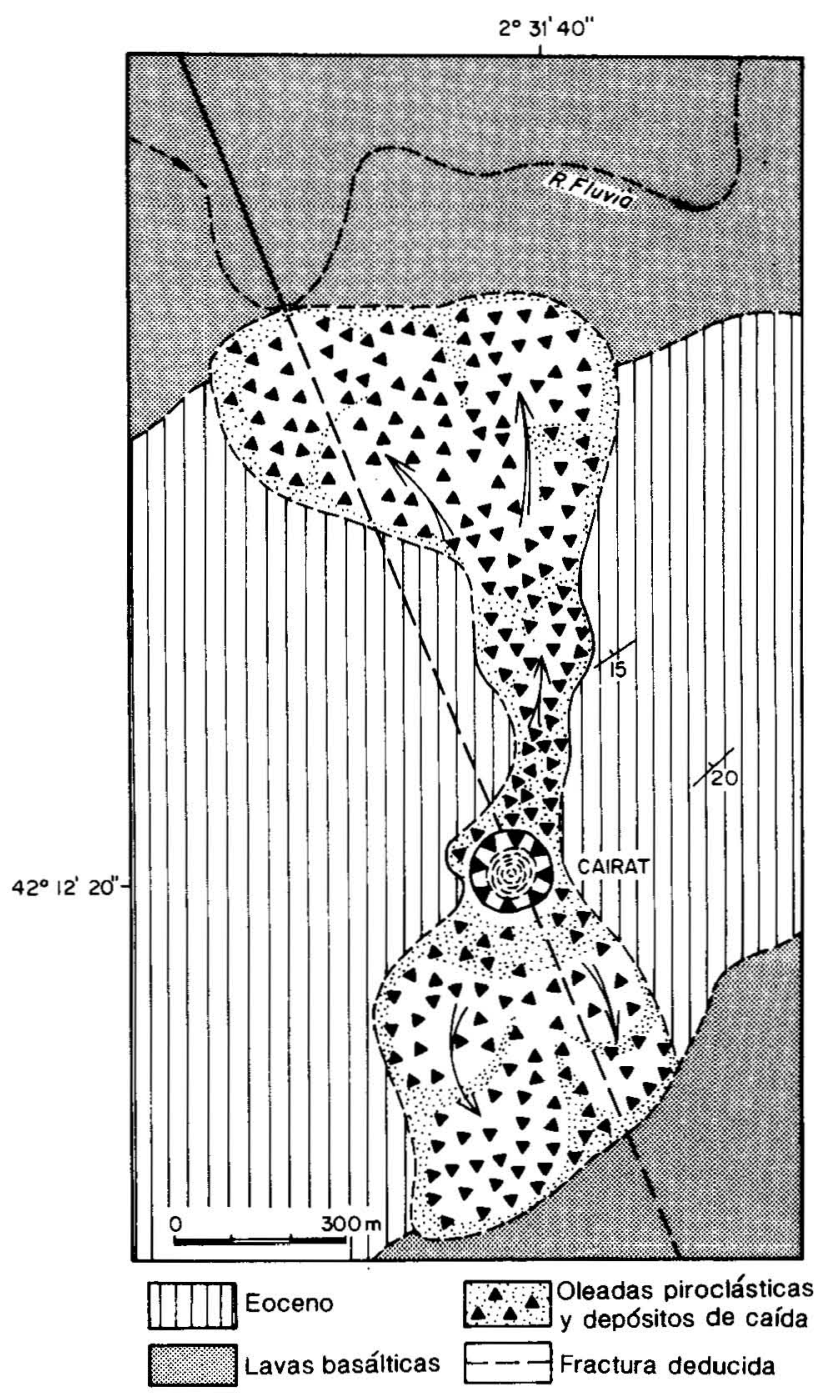

Fig. 6.--Esquema geológico del volcán Cairat.

segunda fase eruptiva se produce una sucesión de explosiones que generan depósitos de oleadas piroclásticas secas, alternando con niveles de caída. Durante la última fase se produce la deposición de un nivel masivo de oleada piroclástica húmeda. Las proyecciones, de distribución bidireccional, se extienden unos $950 \mathrm{~m}$ hacia el $\mathrm{N}$ y unos $600 \mathrm{~m}$ hacia el $\mathrm{S}$, como unos $20 \mathrm{~m}$ de potencia al $\mathrm{N}$ y unos $3 \mathrm{~m}$ al $\mathrm{S}$.

\section{Volcán Closa de Sant Dalmai}

Este volcán se encuentra situado en la Selva, al SW de la ciudad de Girona, y ha sido estudiado en detalle por Martí et al. (1986). Es uno de los edificios más espectaculares de actividad explosi-

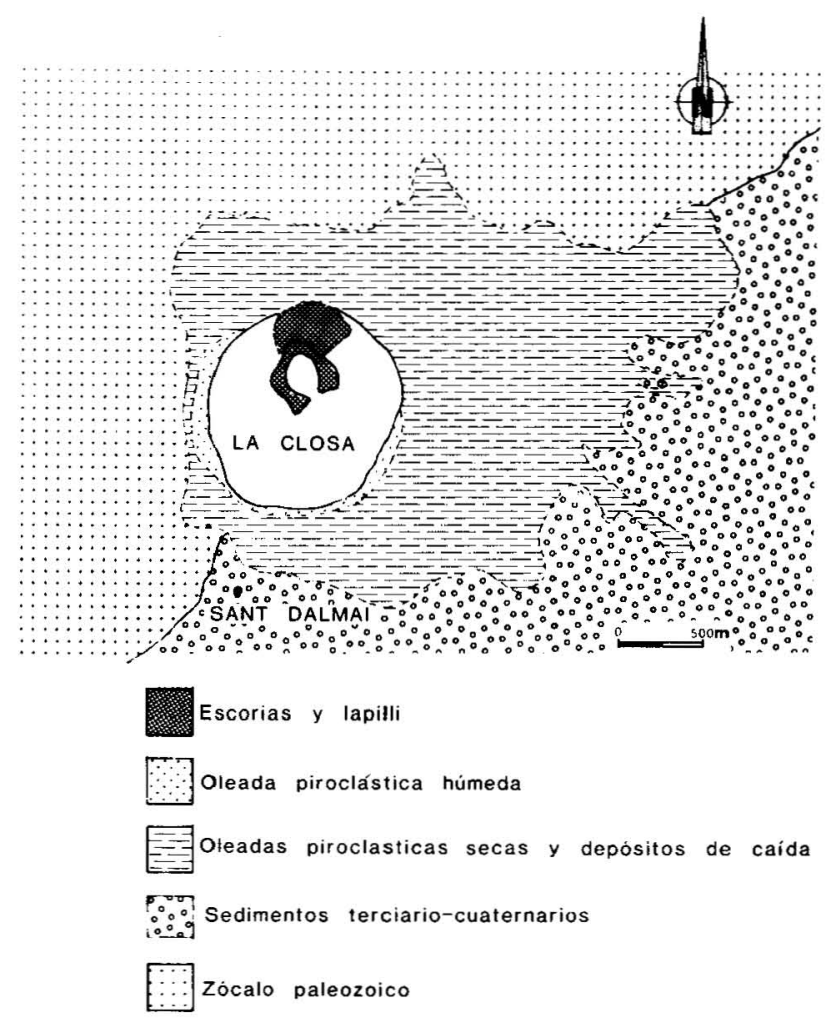

Fig. 7.-Esquema geológico del volcán Closa de Sant Dalmai.

va en este volcanismo. Se trata de un edificio de características morfológicas transicionales entre los de tipo «maar» $y$ «tuff ring», que presenta un cráter circular de $1.200 \mathrm{~m}$ de diámetro, con una profundidad de $43 \mathrm{~m}$, aunque antes del relleno lacustre debió de ser bastante mayor. Está edificado sobre el contacto entre el zócalo hercínico y los materiales sedimentarios terciarios y cuaternarios de la cuenca del río Onyar (fig. 7).

Tanto la morfología como los depósitos piroclásticos indican que se trata de un edificio explosivo generado por varias fases hidromagmáticas que se sucedieron rápidamente dentro de un único episodio eruptivo, el cual puede dividirse en dos ciclos.

En la base del primer ciclo se sitúa una brecha de explosión constituida casi exclusivamente por fragmentos líticos del substrato, lo que indica que la erupción se inicia con una fase freática. A continuación tiene lugar una fase freatomagmática con deposición de niveles alternantes de oleadas piroclásticas secas y de proyección aérea, en los que la participación de material basáltico juvenil es importante (fig. 8). Seguidamente cesa la actividad freatomagmática dando lugar a una fase estromboliana que genera el depósito de escorias y lapillis con que finaliza el primer ciclo. 


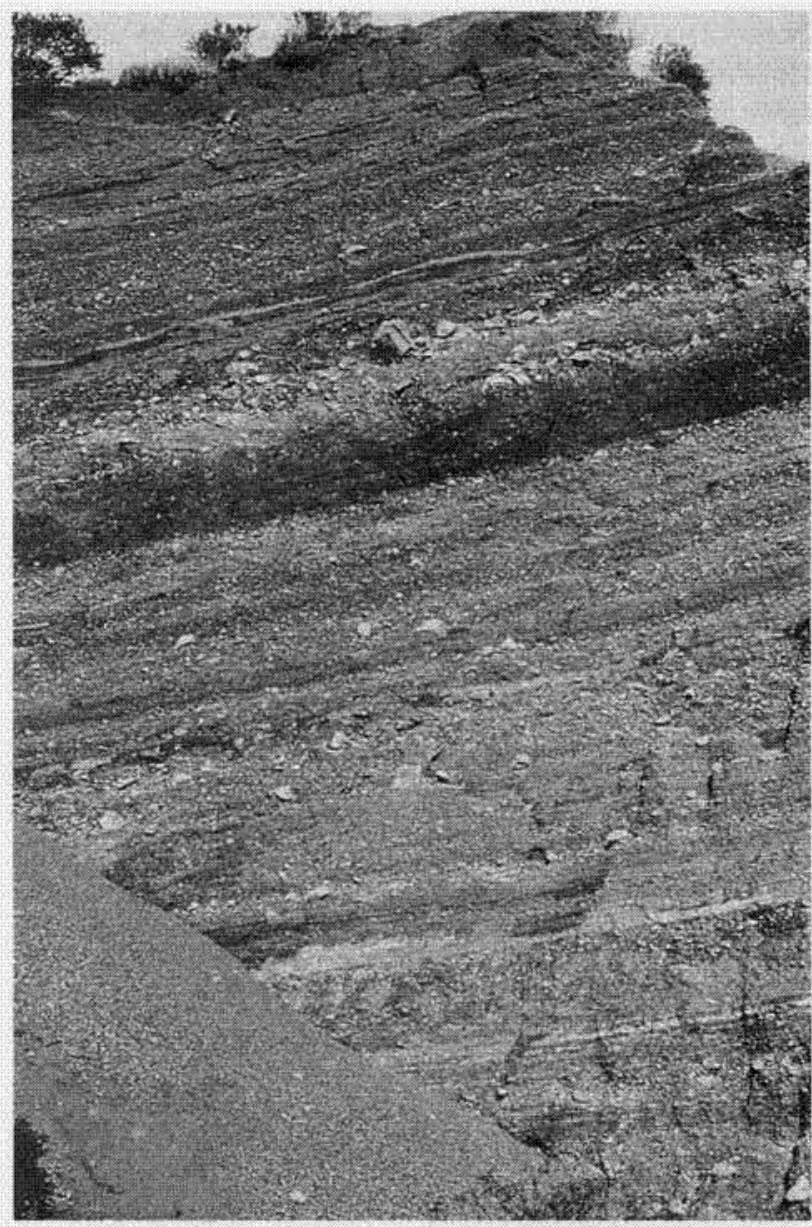

Fig, 8. - Niveles alternantes de oleadas piroclásticas secas y depósitos de proyección aérea, con un nivel de lapillis y escorias intercalado originados por el volcán Closa de Sant Dalmai.

Sin que exista ninguna interrupción de la actividad eruptiva se inicia el segundo ciclo con una brecha de explosión similar a la basal, pero que contiene material basáltico juvenil (lapilli y bombas coliflor), lo que indica una nueva fase freatomagmática. Este tipo de actividad explosiva es también la responsable de la deposición de otra secuencia alternante de niveles de oleadas piroclásticas secas y de caída y, finalmente, de un depósito de oleada piroclástica húmeda (fig. 9), con el que termina la actividad explosiva del volcán.

Después de un período de inactividad importante, tiene lugar un nuevo episodio eruptivo, de menor duracción y de naturaleza estromboliana, que genera un pequeño cono de escorias y lapillis en el interior del cráter de explosión original y da lugar a una pequeña colada basáltica en el flanco $\mathrm{S}$.

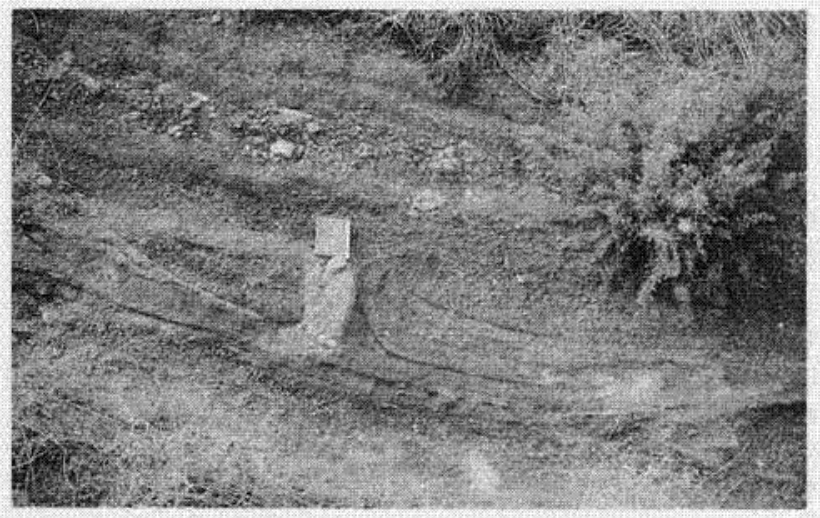

Hig. 9.-Deposito de oleada piroclistica húmeda originado por el volcán Closa de Sant Dalmai.

\section{Discusión}

El estudio de los episodios hidromagmáticos del volcanismo de Olot aporta importantes apreciaciones sobre el volcanismo explosivo en magmas basálticos. En este tipo de magmas, a diferencia de los de composición ácida, el contenido en gases primarios es muy bajo, con lo que la actividad explosiva puramente magmática es de poca intensidad. De este modo la existencia de importantes fases explosivas en esta zona debe explicarse por la interacción entre agua meteórica (superficial o subterránea) con el magma. La modelización de los procesos de interacción agua/ magma ha sido descrita en numerosos trabajos (Sheridan y Wohletz, 1981 y 1983; Wohletz y Sheridan, 1983; Wohletz, 1983; Wohletz y McQueen, 1984).

Del estudio de la secuencia de depósitos piroclásticos que configuran los edificios hidromagmáticos de la zona de Olot se pueden deducir distintas secuencias eruptivas, lo que indica una variedad de mecanismos eruptivos entre estos volcanes. En resumen, pueden considerarse las siguientes secuencias tipo:

1. Fase estromboliana-fase fratomagmática (Can Tià, Garrinada, Santa Margarida).

2. Fase freatomagmática-fase estromboliana (Plaça Ribera).

3. Fase estromboliana-fase freática (o freatomagmática)-fase estromboliana (Racó, Puig de les Medes).

4. Fase estromboliana-fase freática-fase freática (Traiter).

5. Fase freatomagmática-fase estromboliana-fase freatomagmática-fase estromboliana (Puig de Banya de Bòc, Puig de Granollers, Can Simó).

6. Fase freática (Clot de L'Omera). 
7. Fase freática-fase freatomagmática-fase estromboliana. (Closa de Sant Dalmai).

8. Fase freatomagmática (varias fases) (Cairat).

El estudio de los depósitos piroclásticos permite deducir el valor de la relación agua/magma en cada fase hidromagmática. Los depósitos estrombolianos de lapilli y escorias deben interpretarse como puramente magmáticos, aunque en ocasiones puede existir una mínima interacción del magma con agua meteórica. Las brechas de explosión, producidas durante las fases freáticas, están constituidas, en la mayoría de los casos, por fragmentos líticos del substrato. Este hecho indica claramente que en estas fases no tiene lugar una mezcla directa agua/magma, sino que únicamente se produce la explosión de un acuífero al ser sobrecalentado por una lámina de magma que intruye debajo de él.

Los depósitos de oleadas piroclásticos demuestran la interacción directa agua/magma, resultando depósitos distintos en función del valor de esta relación (Sheridan y Wohletz, 1981 y 1983). Se han distinguido oleadas piroclásticas secas, asociadas en ocasiones a niveles de caída, y oleadas piroclásticas húmedas. En ambos casos derivan de explosiones anulares basales producidas cada vez que aumenta de manera considerable la presión de volátiles en el conducto magmático. Las oleadas piroclásticas secas indican una relación agua/magma óptima para que se produzca la máxima transferencia de energía térmica a mecánica (Sheridan y Wohletz, 1981). En estos depósitos el medio de transporte es vapor sobrecalentado que se separa antes de producirse su condensación. Las oleadas piroclásticas húmedas, por el contrario, se emplazan por debajo de la temperatura de condensación, lo que indica un exceso de agua que interacciona con el magma $y$, por tanto, una disminución del sobrecalentamiento y de la energía mecánica.

La diversidad de secuencias eruptivas y la variedad de depósitos producidos en cada una de ellas contrasta con la monotomía composicional que presenta el magma. Por esta razón, las diferencias en el comportamiento eruptivo de los distintos volcanes estudiados hay que buscarla en el efecto conjugado de las distintas características geológicas que muestran los últimos centenares de metros de la corteza debajo de cada centro emisor, con las distintas formas de interacción del agua con el magma, es decir, con las características hidrogeológicas del terreno.

\section{Referencias}

Araña, V.; Aparicio, A.; Martín Escorza, C.; García Cacho, L.; Ortiz, R.; Vaquer, R.; Barberi, F.; Ferrar, G.; Albert, J., y Gassiot, Z. (1983): El volcanismo neógeno-cuaternario de Cataluña: caracteres estructurales, petrológicos y geodinámicos. Acta Geol. Hispánica, 18: 1-17.

Donville, B. (1976): Géologie néogéne de la Catalogne Orientale. Bull. BRGM (deuxiéme série) 4: 177-210.

Guerin, G.; Benhamou, G., y Mallarach, J. M. (1976): Un exemple de fusió parcial en medi continental. El vulcanisme quaternari de Cataluña. Vitrina, 1: 19-26.

López Ruiz, J. y Rodríguez Badiola, E. (1985): La región volcánica mio-pleistocena del NE de España. Estudios geol., 41: $105-126$.

Mallarach, J. M. (1982): Carta geològica de la regió volcànica d'Olot. Litologia i geomorfologia. 1/20.000. Ed Maber, Ajuntament d'Olot.

Mallarach, J. M.; Marti, J., y Claudin, F. (1987): Primeres aportacions al vulcanisme explosiu d'Olot. Revista de Girona, 121 : 69-74.

Marti, J.; Ortiz, R.; Claudin, F., y Mallarach, J. M. (1986): Mecanismos erupticos del volcán de la Closa de Sant Dalmai (Girona). En: Física de los fenómenos volcánicos (Ortiz, R. y Araña, V., edit.). Anales de física, 82 (1-231): 143-153.

Riba, O. (1975): Geotermismo de la zona volcánica de Olot. Nota preliminar sobre posibilidades geotérmicas. Bol. Geol. y Min., -6: 45-62.

Sheridan, M. F. y Wohletz, K. H. (1981): Hydrovolcanic explosions: The systematics of water-pyroclast equilibrium. Science, 212: $1387-1389$.

Sheridan, M. F. y Wohletz, K. H. (1983): Hydrovolcanism: Basic considerations and review. J. Volcanol. Getherm. Res., 17: $1-29$.

Sole Sabaris, Ll. (1982): Observaciones sobre la edad del volcanismo gerundense. Mem. R. Acad. Cienc. y Artes de Barcelona, 34: 359-372.

Solé Sugrañes, L. L. (1978): Alineaciones y fracturas en el sistema catalán según las imágenes LANDSAT-1. Tecniterrae, 22: 6-16.

Tournon, J. (1968): Le volcanisme de la province de Gerona. These $3 .^{\circ}$ Cycle, Univ. de París, 120 págs.

Wohletz, K. H. (1983): Mechanism of hydrovolcanic pyroclast formation: grain-size, scaning electron microscopy and experimental studies. J. Volcanol. Geotherm. Res., 17: 31-63.

Wohletz, K. M. y McQeen, R. G. (1984): Experimental studies of hydromagmatic volcanism. In: Explosive volcanism; Inception, evolution and hazards. National Academy Press, Washington: $158-169$.

Wohletz, K. M. y Sheridan, M. F. (1983): Hydrovolcaníc explosions II. Evolution of basaltic tuff rings and tuffs cones. Amer. J. Sci., 283: 385-413.

Recibido el 6 de noviembre de 1986 Aceptado el 29 de enero de 1987 